\title{
O Teatro Vai à Escola: Anotações sobre as primeiras encenações de Aquele Que Diz Sim, de Kurt Weill e Bertolt Brecht, para públicos escolares
}

\author{
Thereza de Jesus Santos Junqueira \\ Universidade Federal da Bahia - UFBA, Salvador/BA, Brasil \\ E-mail: therezajunqueira@yahoo.com.br
}

\section{Resumo}

Abstract

Discute-se nesse trabalho a concepção coletiva da peça didática e ópera escolar Aquele que diz sim, de Bertolt Brecht e Kurt Weill, a partir de sua segunda encenação, no ano de 1930, para os alunos da Escola Karl Marx, na cidade de Berlim. O que se seguiram foram as mais diversas sugestões de remodelação da dramaturgia. Os alunos não só discordaram da ação proposta, como propuseram novas ações e desfechos. Consequência dessa colaboração foi a transformação de Aquele que diz sim em Aquele que diz não, e a construção de outra versão para Aquele que diz sim, que foi anteposta à primeira. A partir de alguns comentários dos alunos, discute-se as reformulações propostas, em diálogo com a ideia de peça didática.

Palavras-chave

Peça Didática. Pedagogia. Observador Ativo. Construção Coletiva.
This work discusses the collective conception of the didactic play and school opera The one that says yes, by Bertolt Brecht and Kurt Weill, from its second staging, in 1930, for the students of the Karl Marx School in the city of Berlin. What followed were the most diverse suggestions for remodeling dramaturgy. The students not only disagreed with the proposed action, but also proposed new actions and outcomes. The consequence of this collaboration was the transformation of The one who says yes to The one who says no, and the construction of another version for The One who says yes, which was preceded by the first. Based on some student comments, the proposed reformulations are discussed in dialogue with the idea of learning-play.
Learning-play. Pedagogy. Active Observer. Collective Construction. 
Dizer que Aquele que diz sim e Aquele que diz não [Der Jasager und Der Neinsager], é um exemplar do teatro didático de Bertolt Brecht, encenado e publicado originalmente em 1931, e que consiste na aposição de duas peças autônomas, não apresenta novidade para o leitor e espectador brasileiro. Há farta pesquisa sobre as peças didáticas, como o trabalho de Ingrid Dourmien Koudela, que as aborda em seu viés pedagógico e estético (KOUDELA, 1991 e 2019). Todavia, existem informações pouco divulgadas entre nós, a respeito do contexto de sua produção, bem como do processo colaborativo de construção da peças (JUNQUEIRA, 2019).

No final da década de 20 e início da década de 30, Brecht experimentava, ao lado de compositores, dentre os quais Kurt Weill, com música e teatro, tendo alcançado diferentes formatos, sendo os mais expressivos a ópera escolar, a peça radiofônica e a peça didática. Nesse momento, discutia-se, na Alemanha, uma reforma pedagógica, e o movimento da música escolar - do qual Kurt Weill participava - se ocupava dos parâmetros para a educação musical. Desse ponto de partida, ao lado dos estudos sobre Marx, Brecht desenvolveu sua proposta estética e pedagógica.

Aquele que diz sim e Aquele que diz não foi classificada, pelo próprio Brecht, como Lehrstück (peça didática/ peça de aprendizagem). Esse conceito, todavia - ou o que Brecht pretendia com ele -, não restou tão acabado quanto os textos dramáticos apresentados sob essa classificação. No texto Observações sobre a peça didática, de 1956, Brecht elenca as peças que classificou como didáticas:

Para evitar mal-entendidos: das peças pequenas, são didáticas "A peça de Baden-Baden sobre o acordo", "A exceção e a regra", "Aquele que diz sim e Aquele que diz não", "A medida" e "Horácios e Curiáceos" (...). ${ }^{1}$ (BRECHT, Obra Completa, V. 17, 1967, p. 1034, tradução nossa).

1 "Um Mißverständnisse zu vermeiden: Von den kleinen Stücken sind 'Das Badener Lehrstück vom', 'Die Ausnahme und die Regel', 'Der Jasager und der Neinsager', 'Die Maßnahme' und 'Die Horatier und die Kuratier' (...) Lehrstücke".(Brecht, GW, V. 17, 1967, p. 1034)
Apesar das reticências e da ironia - uma vez que o próprio dramaturgo considera, em outros textos sobre as mesmas peças, a impossibilidade de se evitarem mal-entendidos -, seu esforço classificador já oferece pistas para a pesquisa e subsidia a comparação das peças com as demais considerações a respeito. Ressalte-se a exclusão de Voo sobre o oceano, talvez por ser tratada especificamente como peça radiofônica. Ressalte-se também o adjetivo "pequenas", usado pelo dramaturgo para distinguir igualmente essas peças. Além de pequenas, elas são didáticas!

A tradução do termo para o português também não é simples. A versão mais conhecida é peça didática, que estaria próxima à ideia de ensinamento, do verbo lehren (ensinar), cujo radial compõe o vocábulo (Lehr-). Assim, percebe-se que o termo acaba promovendo sua ancoragem na experiência do teatro jesuíta - e seu modelo de doutrinação ou instrução, já noticiado por outros autores, como Ewen (1991) -, bem como a sempre lembrada vinculação do estilo à propaganda marxista.

Koudela (1991) e Gagnebin (2012), conhecedoras da polêmica, preferem a tradução do estilo por peça de aprendizagem - que sublinha a componente experimental da prática -, afastando a ideia de doutrinação ou de panfletagem, com a ressalva de Gagnebin (2012, p. 149), para quem seria mais coerente tratar o estilo de Brecht como Lernstück, com a substituição do lehren (ensinar) por lernen (aprender).

Assim, cumpre problematizar o que se pode entender pelo reconhecido propósito educacional dessas peças, bem como o que se entende por aprender. O aprendizado de determinado estado de coisas requer que seja possível ao menos se posicionar de modo consciente perante o que se dá a conhecer, pois muitos dizem sim, de maneira irrefletida, a vários empreendimentos - sociais, sobretudo -, sem saber o que exatamente está em questão.

Sabe-se que Brecht escreve tendo em mira o espectador e a ativação de sua capacidade crítica, capaz de propor transformações para as mais diversas contingências. $\mathrm{O}$ autor entende, todavia, que os espectadores estão acostumados com o teatro tradi- 
cional, e com a postura passiva que ele solicita, bem como com o oferecimento de uma realidade idealizada, aparentemente harmoniosa, ditada por princípios diferentes daqueles que orientam o seu viver. Por esse motivo, ele ressalta a necessidade de despertar a sua condição de criadores/ produtores, a partir da observação de seus próprios gestos - sua própria conduta. Os espectadores são autantes, na medida em que podem construir e atuar em sua própria dramaturgia.

Nas peças didáticas, o exercício que se propõe é invertido, ou seja, como são peças concebidas para o exercício dos atores, sua proposta é que os atuantes sejam espectadores de si próprios:

Com a peça didática, espera-se que os atuantes, através da realização de determinados modos de ação, da ocupação de determinadas posturas, da repetição de determinadas falas, etc., sejam influenciados socialmente. Para tanto, a imitação de modelos altamente qualificados desempenha um papel importante, da mesma forma que a crítica desses modelos, que pratica outros jogos pensados a partir deles. ${ }^{2}$ (BRECHT, Obra Completa, V. 17, 1967, p. 1024; tradução nossa).

Assim, o primeiro exercício é o de imitar. E, se o objetivo primordial é atuar sem plateia, então a imitação dos gestos e atitudes constantes do texto deve ser praticada como quem atua para si mesmo, como quem está comprometido com o próprio aprendizado. Nesse ponto, já se pode considerar a peculiaridade do exercício, já que o ator tem automaticamente em mira sua plateia - ou a visibilidade de seus atos. Assim, atuar para si mesmo já implica um exercício de desautomatização.

\section{Uma construção coletiva}

Surgida inicialmente em uma parte - Aquele que diz sim [Der Jasager] - enquanto ópera escolar,

2 "Es liegt dem Lehrstück die Erwartung zugrunde, daß der Spielende durch die Durchführung bestimmter Handlungsweisen, Einnahme bestimmter Haltungen, Wiedergabe bestimmter Reden und so weiter gesellschaftlich beeinflußt werden kann./ Die Nachahmung hochqualifizierter Muster spielt dabei eine große Rolle, ebenso die Kritik, die an solchen Mustern durch ein überlegtes Andersspielen ausgeübt wird". a partir da iniciativa e colaboração do compositor Kurt Weill, que teve acesso, em 1929, a uma tradução da escritora e tradutora Elisabeth Hauptman, para a peça Taniko ${ }^{3}$, foi apresentada e reapresentada por e para alunos das escolas de Berlim, nos anos de 1930 e 1931, tendo se transformado apenas posteriormente em Aquele que diz sim e Aquele que diz não. Em sua versão final, Aquele que diz sim e Aquele que diz não consiste em duas peças curtas que, ressalvadas as finalizações distintas da segunda parte, podem parecer idênticas em uma primeira leitura. Contam a história de um menino, que sai em expedição com seu professor e alguns estudantes para "a cidade do outro lado das montanhas" (BRE$\mathrm{CHT}, 2013$, p. 31, tradução nossa), com o objetivo de buscar remédios e orientações médicas para a cidade onde moram e para a mãe do menino, que está doente. Na segunda parte das peças, iniciada a expedição, o menino logo adoece. A partir desse ponto, cada peça oferece uma finalização diferente, o que já pode ser vislumbrado no título da obra. Em Aquele que diz sim, o menino concorda com uma tradição que descarta aqueles que adoecem, para que a expedição prossiga. E, em Aquele que diz não, o menino contradiz a tradição, em favor de sua vida e de um novo aprendizado que poderia ser feito.

Após a estreia de Aquele que diz sim, em 1930, incomodou a Brecht, todavia, que os aplausos vinham também de um público conservador:

A arbitrariedade das interpretações, e também o aplauso vindo do lado errado, pareceu surpreender Brecht, quando ele, voltando do sul da França para Berlin, tomou conhecimento das discussões em torno de Aquele que diz sim. Por isso ele aprovou a possibilidade de avaliar a ópera escolar em contato

30 texto que foi traduzido por Elisabeth Hauptmann - e publicado, em 1929, com o título Tanikō oder Der Wurf ins Tal [Tanikō ou O lançamento no vale] - consistia em uma versão inglesa da fábula japonesa Tanikō, intitulada The Valley-Hurling [O lançamento no vale], elaborada por Arthur Waley alguns anos antes. A tradução de Hauptmann acompanha, de modo fidedigno, a versão inglesa, a qual apresenta, por sua vez, uma adaptação do mito japonês, relativizando seu conteúdo religioso propriamente dito. 
com aqueles para quem ela teria sido escrita. ${ }^{4}$ (KRABIEL, 2001, p. 249, tradução nossa).

A ópera escolar foi então apresentada para um público de alunos de uma escola téncnica comunitária de Berlim, a Escola Karl-Marx do Bairo Neukölln, no outono de 1930. O que se seguiu foram as mais diversas sugestões de remodelação da dramaturgia. Os alunos não só discordaram da ação proposta, como propuseram novas ações e desfechos. Consequência dessa colaboração foi a transformação de Aquele que diz sim em Aquele que diz não, e a construção de outra versão para Aquele que diz sim, que foi anteposta à primeira. Desse modo, o texto final, ao qual se tem acesso, é composto por Aquele que diz sim II e Aquele que diz não.

A começar pela sugestão de Weill e pela tradução de Hauptmann, percebem-se as muitas mãos envolvidas nos intentos de Brecht, até que se chegasse à peça como é conhecida. Neste ensaio, apresenta-se os comentários dos alunos da Escola Karl Marx que assistiram a primeira versão de Aquele que diz sim, apresentada como peça autônoma, e que será adiante referida como Aquele que diz sim I.

Em Aquele que diz sim I, ao contrário da conhecida versão final, não existe epidemia na cidade onde mora o menino. Trata-se de uma expedição científica, em busca de ensinamentos: a mãe do menino está doente, há médicos na outra cidade, mas não há epidemia, nem outros doentes na cidade onde eles moram. Quando o menino adoece, ele não pode continuar a expedição, porque, naquele ponto, a montanha apresenta uma formação difícil de ser atravessada, de modo que cada pessoa deve se agarrar à rocha com as duas mãos, sendo impossível levar alguém consigo. Assim, estando o menino doente, ele não conseguiria atravessar sozinho o obstáculo.

4 Die Beliebigkeit der Auslegung, auch der Beifall von der falschen Seite, scheinen B. überrascht zu haben, als er, aus Südfrankreich nach Berlin zurückgekehrt, Kenntnis von den Diskussionen um den Jasager erhielt. Er begrüßte deshalb die Möglichkeit, die Schuloper im Kontakt mit jenen zu überprüfen, für die sie geschrieben worden war. (KRABIEL, 2001, p. 249).
Trata-se de um mito polêmico, a despeito de sua apresentação ou reformulação por Brecht. Conforme comentado por Weill e pela crítica da época, ele permite a reflexão sobre a vida em comunidade e sobre a relação entre seus membros e o todo, para que se questione - o texto não dá respostas - até que ponto cada indivíduo responde pela permanência do tecido social.

\section{- A recepção pelos alunos da escola Karl Marx}

Ante as múltiplas e diversas críticas que Aquele que diz sim I recebeu, Brecht e Weill resolveram apresentar a ópera escolar ao público para o qual ela teria sido concebida, com vistas a ouvir comentários e receber sugestões, e foi com esse intento que o trabalho foi apresentado na Escola Karl Marx.

Depois da apresentação, o texto foi discutido com alunos de várias idades, de 11 (onze) a 20 (vinte) anos, provenientes do ensino regular e do curso profissionalizante, e suas contribuições foram compiladas em um protocolo construído pelos professores da escola ${ }^{5}$, o qual serviu de inspiração e motivação para a escritura da última versão da peça, Aquele que diz sim e Aquele que diz não, por Brecht, dessa vez sem a contribuição de Weill.

Os comentários descrevem as impressões dos espectadores, e sugerem modificações para a dramaturgia, como nesse excerto de um aluno oriundo do ensino médio, não identificado:

[...] A peça não é apropriada para nossa escola, pois o professor da história é muito sangue-frio e nossa escola pode ser comparada com ele... A pesquisa não é tão importante como uma vida humana... [... $]^{6}$ (BRECHT, 2013, p. 59, tradução nossa).

5 O protocolo a que se tem acesso na obra completa de 1967 (reeditada em 1982), bem como na edição de Der Jasager e Der Neisager organizada por Peter Szondi em 1966, trata-se de uma versão reduzida, com cortes dos depoimentos, os quais teriam sido feitos pelo próprio Brecht.

6 [...] Das Stück ist nicht geeignet für unsere Schule, da der Lehrer des Spieles sehr kaltblütig ist und damit unsere Schule verglichen werden kann... Die Forschung ist nicht so wichtig wie ein Menschenleben... [...] (BRECHT, 2013, p. 59). 
Percebe-se que o espectador, ao mencionar o professor e compará-lo com os de sua escola, ainda organiza seu olhar com base em uma postura representacional, como quem busca referências dadas a priori, pois pensa na existência de uma escola, cujo professor é inescrupuloso. Mas não fica nessa observação, uma vez que traça uma comparação e avalia se a peça seria adequada para o específico contexto da recepção. A identificação inicial não aprisiona o espectador no universo da história, mas o projeta, imediatamente, para seu próprio contexto. Esse aluno continua seus comentários sugerindo possibilidades diferentes para a dramaturgia:

[...] Mantém-se a peça; o menino não pode continuar, então fica e espera. A fome o obriga a se jogar de livre vontade no vale... Deveria se seguir ainda um epílogo judicial... Mantém-se a peça; o menino é levado junto com grande esforço. No caminho dois escorregam e despencam... Amarrar o menino e leva-lo junto... ${ }^{7}$ (BRECHT, 2013, p. 59, tradução livre).

$O$ aluno sugere três prosseguimentos possíveis. No primeiro, o menino é deixado e se joga no vale, por sua própria vontade e necessidade, o que deveria ser seguido de um epílogo judicial, certamente para avaliar qual vontade afinal teria sido feita, ou acerca das responsabilidades pelo infortúnio. Na segunda, o menino é levado junto, mas isso conduz a um acidente, levando outras pessoas a caírem no vale; e na terceira, o menino é amarrado, talvez para não permitir que ocorra o acidente.

A fala desse aluno parece elaborar progressivamente o aprendizado que poderia ser feito na situação. Deixar o menino morrer pelo grupo não é algo óbvio, mesmo que essa morte seja causada por ele próprio, pela fome que sentiu ao ser deixado no caminho, razão pela qual se faz necessária a sequência judicial.

7 [...] Das Spiel bleibt; der Junge kann nicht mehr weiter, bleibt aber und wartet. Der Hunger zwingt ihn, und er stürzt freiwillig in die Tiefe... Es soll noch ein gerichtliches Nachspiel folgen... Stück bleibt; der Junge mit großen Anstrengungen mitgenommen. Auf dem Wege rutschen zwei ab und stürzen ab... Durch Anseilen den Jungen mitnehmen... (BRECHT, 2013, p. 59)
Percebe-se a consciência do caráter ficcional da trama. Ao refletir e pensar sobre outros finais possíveis, os espectadores manipulam o texto, que não é tomado como definitivo, ou como se uma realidade fosse. É ficcional, artístico e, portanto, construído. E se foi assim construído, poderia ser igualmente de outra maneira.

Dentre os comentários, há uma crítica à fábula, feita também por alunos oriundos do Ensino Médio, que marca a ausência de justificativa, pelo menino, para sustentar sua escolha. Parece uma elaboração dessa primeira crítica, que procura por caminhos em que o (auto-)lançamento do menino no vale, pudesse ser justificado:

Mais vozes aderem à opinião de que o des-
tino do Jasager é apresentado de modo que
não se pode ver sua necessidade. Por que
toda a coletividade não volta atrás e salva
seu membro doente, ao invés de matá-lo?
...Desse lado vem a sugestão de realizar a
cena da subida da montanha e da queda
de modo mais forte, e talvez assim dar cau-
sa ao necessário entendimento... A mística,
que a ópera leva a cabo, não é recebida de
modo confortável... A motivação da ação não
é suficientemente clara... Grupo do OI, 18
anos. ${ }^{8}$ (BRECHT, 2013, p. 59, tradução livre).

H. Zeschel, de 17 anos, relata que a maioria de seus colegas aprecia a peça, e sugere uma modificação externa, no programa, para ressaltar a plausibilidade dos acontecimentos apresentados:

[...] Grande parte da sala entende que a peça deve continuar como está. Por ocasião da apresentação, o programa deveria, no máximo, conter um esclarecimen-

8 [...] Mehrere Stimmen schließen sich der Ansicht an, daß das Schicksal des Jasagers nicht so dargestellt ist, daß man seine Notwendigkeit sieht. Warum ist nicht die ganze Gesellschaft umgekehrt und hat das kranke Glied gerettet, anstat es zu töten? ... Von dieser Seite kommt der Vorschlag, die Szene des Bergsteigens und des Abstürzes stärker zu realisieren, und dadurch vielleicht das nötige Verständnis herbeizuführen... Die Mystik, die die Oper durchzieht, wird nicht angenehm empfunden... Die Motiviereung der Handlung ist nicht deutllich (real) genug... Gruppe der Ol, 18 Jahre. (BRECHT, 2013, p. 59). 
to... Nessa introdução, deve-se tentar convencer o espectador da necessidade desse acontecimento que é brutal, embora verídico. H. Zeschel, Ulb, 17 anos. ${ }^{9}$ (BRECHT, 2013, p. 63, tradução livre).

Esse aluno parece atentar para a possível descrença do espectador quanto à fábula, como destacado por outros alunos, como M. Tautz, de 14 anos, quem entende que a peça poderia ser compreensível apenas em seu contexto de origem, sendo útil, no contexto em que é encenada, apenas para mostrar o caráter prejudicial da superstição:

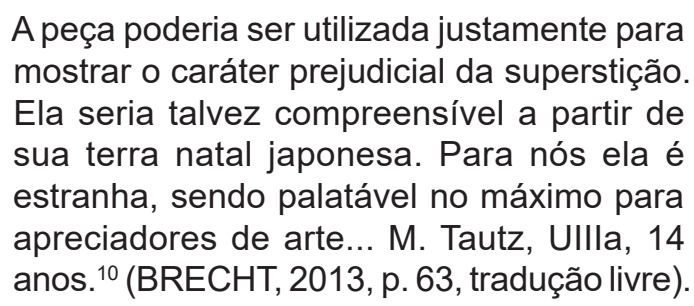

M. Tautz ressalta como a peça parece estranha em outro contexto que não compartilha aquela tradição. Se no Japão o sacrifício do menino poderia ser compreensível, na Alemanha ele soa estranho. Esse espectador também tenta realizar uma compreensão pautada pela referência. A peça apresentada não apresenta, em seu olhar, conexão com a realidade. Mas, ao mesmo tempo, ele não acredita na verdade da peça, a fábula é criticável, por ser inaceitável, segundo o olhar do aluno, no contexto de sua recepção.

Talvez a sugestão do aluno H. Zeschel, acerca da apresentação de esclarecimentos no programa da peça, permitiria uma ampliação de seus efeitos,

9 [...] Der größte Teil der Klasse ist der Meinung, daß das Stück unbedingt so bleiben müsse. Bei der Aufführung sei höchstens das Programm mit einer Erklärung zu verstehen... Es muß in dieser Einleitung versucht werden, den Zuschauer von der Notwendigkeit dieser brutalen, jedoch nicht lebensunwahren Sache zu überzeugen. H. Zeschel, Ulb, 17 Jahre. (BRECHT, 2013, p. 63).

10 Man könnte das Stück gerade dazu benutzen, die Schädlichkeit des Aberglaubens zu zeigen. Es wäre vielleicht aus seiner japanischen Heimat heraus verständlich, uns aber fremd, höchstens etwas für künstlerische Feinschmecker... M. Tautz, UIlla, 14 Jahre. (BRECHT, 2013, p. 63). com o alcance de mais espectadores, como M. Tauzt e, além disso, fomentaria reflexões mais implicadas, em que aqueles que assistem pudessem marcar melhor o que difere seu lugar daquele encenado.

W. Berg, de 12 anos, destaca o papel da música, e sua importância para evitar a aclimatação total do espectador. O aluno percebe que a música não acompanha o texto, que ela é na maior parte ligeira ao contrário da gravidade do texto, e anota os efeitos que isso produz:

[...] É completamente novo para nós que, nessa peça, a música não acompanhe o texto. Ao final, quando o menino está morto, outro compositor deixaria tocar provavelmente um acorde festivo e prolongado como acompanhamento do coro. Por isso, [porque a música não acompanha o texto] fica-se tão assustado com essa cena, que se guarda apenas essa parte na cabeça e não se tem clareza sobre outras partes. Isso acontece em razão da abordagem ligeira de Bertolt Brecht. A música na ópera de Bertolt Brecht é constantemente ligeira. Apenas quando o menino está morto, a música para o canto do coro "Ele estava morto" se apoia fortemente em uma dança atual. Através da abordagem ligeira e leve de Brecht tem-se uma visão conveniente da ópera, pois ela não é penetrante em nenhuma parte, de modo a tirar lágrimas de alguém, e também não desviante, de modo que se pudesse dizer que não se teria nenhuma ideia de alguma parte, mas tão somente do todo da ópera... [...] W. Berg, Klasse IVa, 12 anos. ${ }^{11}$ (BRECHT, 2013, p. 60, tradução livre).

11 [...] Völlig neu ist uns, daß in diesem Stück die Musik nicht mit dem Text gleichläuft. Zum Schluß, als der Knabe tot ist, würde ein anderer Komponist wahrscheinlich einige feierliche, langanhaltende Akkorde als Begleitung des Chors laufen lassen. Dadurch ist man von dieser Szene so erschüttert, daß man nur diesen Teil im Kopf behält und sich über anderer Teile gar nicht im klaren ist. Dieses wird durch Bertolt Brechts flotte Art beseitigt. Die Musik ist in Bertolt Brechts Oper immer gleichbleibend flott. Als nun der Knabe tot ist, ist die Musik zum Gesang des Chors „Und er war tot“ sehr stark an einen jetzigen Tanz angelehnt. Man hat durch die leichte flotte Art Bertolt Brechts einen Überblick über die Oper, der sehr vorteilhaft ist, denn sie ist an keiner Stelle so ergreifend, daß einem direkt Tränen ausgepreßt werdern, und auch nicht so ablehnend, daß man sagen kann, man hätte über einzelne Stellen gar keinen Überblick, sondern man könne sich nur die Oper als Ganzes vorstellen... [...] W. Berg, Klasse IVa, 12 Jahre. (BRECHT, 2013, p. 60). 
E continua, quanto à fábula, sugerindo que o menino deveria hesitar, que não deveria aceitar tão imediatamente seu destino:

[...] Infelizmente, o texto da ópera não é muito convincente em uma parte. O menino é quase idealizado como um mártir, pois ele se conduz livremente à morte, sem resistência. Quase se poderia dizer que o menino aceita o desejo dos camaradas, porque é esse o seu desejo, que ele não pronuncia. Como seria se o menino hesitasse um pouco? Em nossa opinião, a ópera teria também um efeito mais importante, se o menino hesitasse... De modo geral nossa opinião é que a peça só é familiar àqueles poucos que também poderiam conduzir alunos sem muito esforço... [...] W. Berg, Klasse IVa, 12 anos. ${ }^{12}$ (BRECHT, 2013, p. 60, tradução nossa).

Quanto ao destino do menino, W. Berg sugere outra finalização, com vistas a mitigar a culpa dos estudantes por sua morte. Sem adentrar ou analisar o conteúdo dessas declarações, ou suas motivações, pode-se perceber a disparidade das visões de mundo circundantes e o desafio que elas poderiam oferecer a Brecht:

[...] Ou o estudante também fica doente e a expedição tem que retornar, apesar de que o menino queira que ele seja lançado no despenhadeiro. Ou eles devem tentar atravessar a fenda e, com isso, o menino despenca, ou talvez todos, de maneira que depois nenhum tenha culpa pela morte do

12 [...] Leider ist der Text in der Oper an einer Stelle nicht sehr überzeugend. Der Knabe wird fast zu einem Märtyrer verklärt, denn er zieht freiwillig, ohne Widerstand, in den Tod. Man könnte fast meinen, der Knabe geht auf die Wünsche der Kameraden ein, weil es auch seine Wünsche sind, die er allerdings nicht ausspricht. Wie wäre es, wenn der Knabe erst ein wenig zaudert? Nach unserer Meinung hätte die Oper dadurch auch eine Hauptwirkung, wenn der Knabe erst ein wenig zaudert... Im ganzen ist unsere Meinung, daß das Stück zu den wenigen gehört, die auch Schüler ohne große Anstrengung aufführen können... [...] W. Berg, Klasse IVa, 12 Jahre. (Brecht, 2013, p. 60). menino... [...] W. Berg, Klasse IVa, 12 anos. ${ }^{13}$ (BRECHT, 2013, p. 60, tradução nossa).

Outro aluno, B. Korsch, de 10 anos, declara que relatará apenas os comentários dos colegas. Da sequencia de falas, pode-se deduzir que houve uma discussão na sala, pois há continuidade e contraposição entre algumas. Há mais posicionamentos divergentes, e até mesmo um relato que concorda com o fim trágico do menino, porque a presença de um membro doente não colaboraria com a expedição. Outro recupera sua referência pessoal em uma viagem nas montanhas, mas não consegue projetar uma situação limite, como a relatada:

Eu escrevo apenas o que os alunos dizem. "A ópera é muito triste." "Ela não soa bem." "Na ópera canta-se." "As frases são estranhas e o verso não as acompanha." "Eu gosto muito da peça, somente acho que não está certo com o costume." "É bom que os doentes sejam jogados lá em baixo (sic!), senão ele se martiriza mais." "Isso é assassinato." "Eu também estive em cabanas nos Alpes, mas lá sempre achamos algo para comer, todas as noites chegava alguém, a quem a louça pertencia." [...] B. Korsch, Vlb, 10 anos. ${ }^{14}$ (BRECHT, 2013, p. 61, tradução nossa).

E continua, apresentando comparações feitas pelos alunos entre o que é descrito na peça, e a situação deles próprios, por exemplo, como em "Nós

13 [...] Entweder soll der Student auch krank werden und die Expedition soll umkehren, obwohl der Knabe will, daß man ihn den Felsen hinunterstürzt. Oder sie sollen versuchen, über den Pfad zu kommen, und dabei soll der Junge abstürzen oder auch alle, so daß nachher keiner die Schuld an die Tod des Knaben hat... [...] W. Berg, Klasse IVa, 12 Jahre. (BRECHT, 2013, p. 60).

14 Ich schreibe nur, was die Schüler sagen. „Die Oper ist sehr traurig. " "Sie klingt nicht gut". "In der Oper wird doch gesungen“. „Es ist komische Satzstellung, und der Vers gehört nicht dazu. "„Das Stück gefällt mir sehr gut, nur das mit dem Brauch ist, glaube ich, nicht richtig." "Es ist gut, daß man die [sic!] Kranken runterwirt, denn sonst quält er sich mehr." "Das ist ja Mord". "Ich war auch in den Alpen in Hütten, da haben wir aber immer was zu essen gefunden, da kommt jeden Abend jemand hin, dem das Geschirr gehört". [...] B. Korsch, Vlb, 10 Jahre. (BRECHT, 2013, p. 61). 
não somos fracotes", ou o relato que apresenta como justificativa para o autosacrifício, a saúde da mãe:

[...] "Isso com o Jasager é seguinte, ele diz sim sem o saber, e o mesmo acontece com a mãe. Mas eles o trouxeram para cima, é o que se ouve, e eu penso, que não se poderia levar ninguém para lá." "Somente até o abismo." "A peça é mais apropriada para adultos." "Nós não somos fracotes." "Eu acho que ele deveria escrever mais claro." "Eu acho que esse coro é apenas para fedelhos." "Eu acho, que ele disse sim porque ele queria ter sua mãe saudável de novo, e se ele dissesse não, os outros não chegariam até os médicos." [...] B. Korsch, VIb, 10 anos. ${ }^{15}$ (BRECHT, 2013, p. 61, tradução nossa).

Em seguida, aparece um contra-argumento a respeito da posição da mãe, e outras considerações que levam a entender a necessidade de que as razões do menino fossem explicitadas:

[...] "Não é claro o que eles realmente querem alí." "Eu gostaria de dizer, quando sua mãe souber de sua morte, ela vai ficar mais doente." "Como eles o jogam lá embaixo?" "Eu acho que uma vida jovem é mais valiosa que uma velha". "Seria melhor se o menino dissesse, eu quero pensar, e se ouvisse um monólogo dele, assim as razões ficariam claras." B. Korsch, VIb, 10 anos. ${ }^{16}$ (BRECHT, 2013, p. 61, tradução nossa).

$15[\ldots]$ „Das mit dem Jasager ist so, er sagt ja, ohne es zu wissen, und genauso ist es mit der Mutter. Aber sie haben ihn doch, so viel man hört, hinaufgetragen, und ich denke, man kann da niemanden tragen." „Nur bis zum Abgrund." „Das Stück ist eher für Erwachsene." Wir sind doch keine Trauerklöße. " „Ich meine, er soll verständlicher schreiben." "Ich finde, das mit dem Chor ist nur für Primaner." "Ich glaube, daß er ja gesagt hat, weil er seine Mutter gesund haben wollte, und wenn er nein gesagt hätte, wären die andern auch nicht zu den Ärzten gekommen." [...] B. Korsch, VIb, 10 Jahre. (BRECHT, 2013, p. 61).

16 [...] "Was wollen die eigentlich da, das ist unklar." „Ich möchte sagen, wenn seine Mutter von seinem Tode erfährt, sie doch noch kränker wird." "Wie werfen sie ihn denn runter?" "Das ist doch grausam. " "Vielleicht is einer zäh und lebt noch." "Ich meine, ein junges Leben ist mehr wert als ein altes." „Es wäre schöner, wenn er sagte, ich will es mir überlegen, und man hört ein Selbstgespräch vom Jungen, da werden einem die Gründe klar." B. Korsch, VIb, 10 Jahre. (BRECHT, 2013, p. 61).
Gerhard Krieger, 20 anos, aluno do curso profissionalizante, entendeu que a questão em evidência na ópera seria um apelo à solidariedade da sociedade para com seus membros necessitados. E levantaram uma questão a respeito da ponderação entre vantagem e sacrifício, para averiguar se a vantagem auferida com a continuidade da expedição poderia justificar o sacrifício de um de seus integrantes.

[...] A coletividade deve agir de modo solidário, conduzir de volta o doente incapaz... A coletividade não pode, de maneira alguma, exercer uma pressão moral sobre o menino para alcançar seu consentimento... A pergunta é para testar se a vantagem dos vencedores é tão grande que o sacrifício do menino seja necessário. Gerhard Krieger (Curso profissionalizante), 20 anos. ${ }^{17}$ (BRECHT, 2013, p. 63, tradução nossa).

Os alunos continuavam a contar a história, justificando as escolhas feitas e outras que poderiam ter sido feitas. Justamente com essa atitude, vinda de uma crítica negativa dos alunos, Brecht realizava um de seus propósitos. Assim, a peça continuava produzindo efeitos, ou seja, continuava ativa, conduzida por cada aluno, em seus comentários e críticas. Mas como o autor incorporou essas contribuições?

As modificações realizadas em Aquele que diz sim II refletem as demandas dos alunos. Ao justapor Aquele que diz não à nova versão de Aquele que diz sim, Brecht parece atender à demanda por motivação, iluminando a arbitrariedade e modificabilidade do destino do menino.

Assim, a natureza da expedição, que mudou de uma expedição científica para uma expedição de socorro, agrega uma possível justificativa para a suposta necessidade de continuação até a cidade dos médicos, embora não apresente um julgamento de valor sobre a atitude.

17 [...] Die Gesellschaft muß solidarisch handeln, den unfähigen Kranken zurückführen... Die übrige Gesellschaft darf auf keinen Fall einen moralischen Druck auf den Knaben ausüben, um seine Einwilligung zu erlangen... Die Frage ist zu prüfen, ob der Vorteil des Gewonnenen so groß ist, daß der Opfertod des Knaben notwendig ist. Gerhard Krieger (Arbeiter-Kurs), 20 Jahre. 


\section{O teatro vai à escola}

Nas colaborações dos alunos à apresentação de Aquele que diz sim, percebe-se não apenas sua auto implicação, mas também seu empenho em sugerir novas chaves e prosseguimentos para a peça, o que os leva à categoria de atuantes, ou observadores ativos, embora, em princípio, apenas discursivamente ativos. É a peça didática que estava em ação, e que se constituía progressivamente, incorporando novos participantes ao exercício.

O palco se abriu para a experiência cognitiva dos alunos da Escola Karl Marx, uma vez que eles puderam estabelecer comparações entre a dramaturgia da peça e sua própria condição. Os alunos pareceram estimulados a criar suas próprias perguntas $\mathrm{e}$ respostas diante daquelas propostas pela dramaturgia, em um movimento de inclusão, através da identificação promovida pelo cenário escolar, e de espanto, em razão do fim trágico do menino, (aparentemente) incompatível com o contexto de sua recepção.

No texto Teoria da pedagogia (Theorie der Pädagogien) (GW, v. 17, p. 1022), Brecht, ao desenvolver uma justificativa para a utilização de jogos teatrais nos processos educativos, projeta a utilidade do teatro na sala de aula, em um movimento inverso ao esperado: é o teatro que vai à escola. Nas peças didáticas, o teatro se coloca como aprendiz.

O que esse deslocamento pode dizer? O teatro precisa aprender o processo de ensino-aprendizagem; como nas peças didáticas, precisa aprender a ser palco e plateia simultaneamente, seja ao convocar a plateia para fazer parte do espetáculo da aprendizagem, seja ao observar seus próprios gestos e ser plateia/ espectador de si mesmo.

$E$, nesse processo, o teatro ensina para a escola que a aprendizagem não é apenas um processo mental; que, para aprender, é preciso implicar todo o corpo, porque é como o ser humano está no mundo. Para compreender as personagens, os atores precisam estudar não apenas suas falas, mas, também, seus gestos e comportamentos.

\section{Referências}

BRECHT, Bertolt. Der Jasager und der Neinsager, 29. Auflage. Suhrkamp Verlag, p. 219, 2013.

BRECHT, Bertolt. Anmerkungen zu Stücken und Aufführungen. Gesammelte Werke in 20 Banden. V. 17. Frankfurt am Main: Surkamp Verlag, 1967.

EWEN, Frederic. Bertolt Brecht: sua vida, sua arte, seu tempo. Rio de Janeiro: Editora Globo, 1991.

GAGNEBIN, Jeanne-Marie. Brecht e Benjamin: peça de aprendizagem e ordenamento experimental. In: Viso. Cadernos de estética aplicada, v. VI, n. 11, pp. 145-151, jan-jun, 2012

JUNQUEIRA, Thereza de Jesus Santos. Rumo à cidade do outro lado das montanhas: um estudo genealógico de Aquele que diz e Aquele que diz não de Bertolt Brecht. Salvador: UFBA, 2019. (Tese de doutorado em Literatura e Cultura).

KOUDELA, Ingrid Dormien; CONCILIO, Vicente. Protocolos e a pedagogia do Teatro - da tradução dos protocolos de estudantes sobre Aquele que diz sim aos protocolos do "trabalho alegre". In: Urdimento, Florianópolis, v. I, n. 34, p. 246-255. mar/abr., 2019.

KOUDELA, Ingrid Dormien. Brecht: um jogo de aprendizagem. São Paulo: Perspectiva, 1991.

KRABIEL, Klaus-Dieter. Die Lehrstücke. In.: KNOPF; Jan (Hrg.) Brecht Handbuch. Stücke. Stuttgart/Weimar: Verlag J. B. Metzler, 2001.

Recebido: 07/01/2021

Aceito: $27 / 04 / 2021$

Aprovado para publicação: 30/05/2021 
Este é um artigo de acesso aberto distribuído sob os termos de uma Licença Creative Commons Atribuição 4.0 Internacional. Disponível em: http://creativecommons.org/licenses/by/4.0.

This is an open-access article distributed under the terms of the Creative Commons Attribution License 4.0 International. Available at: http://creativecommons.org/licenses/by/4.0.

Ce texte en libre accès est placé sous licence Creative Commons Attribution 4.0 International. Disponible sur: http://creativecommons.org/licenses/by/4.0. 